\title{
Banking applications of FCM models
}

\section{Hatwágner, Miklós F.}

Springer Verlag

2019

Hatwágner , M F , Vastag , G , Niskanen , V A \& Kóczy , L T 2019 , Banking applications of FCM models . in M E Cornejo , L T Kóczy, J Medina \& A E De Barros Ruano (eds), Trends in Mathematics and Computational Intelligence. Studies in Computational Intelligence, vol. 796 , Springer Verlag . https://doi.org/10.1007/978-3-030-00485-9_7

http://hdl.handle.net/10138/314650

https://doi.org/10.1007/978-3-030-00485-9_7

acceptedVersion

Downloaded from Helda, University of Helsinki institutional repository.

This is an electronic reprint of the original article.

This reprint may differ from the original in pagination and typographic detail.

Please cite the original version. 


\title{
Banking applications of FCM models
}

\author{
Miklós F. Hatwágner ${ }^{1}$, Gyula Vastag ${ }^{2}$, Vesa A. Niskanen ${ }^{3}$ and László T. Kóczy ${ }^{4}$ \\ ${ }^{1}$ Department of Information Technology, Széchenyi István University, Győr, Hungary \\ miklos. hatwagneresze.hu \\ ${ }^{2}$ Department of Leadership and Organizational Communication, Széchenyi István University, \\ Györ, Hungary \\ vastag.gyulaesze.hu \\ ${ }^{3}$ Dept. of Economics \& Management, University of Helsinki, Helsinki, Finland \\ vesa.a.niskanen@helsinki.fi \\ ${ }^{4}$ Department of Information Technology, Széchenyi István University, Győr, Hungary and De- \\ partment of Telecommunications and Media Informatics, Budapest University of Technology \\ and Economics, Hungary \\ koczy@sze.hu, koczy@tmit.bme.hu
}

\begin{abstract}
Fuzzy Cognitive Map (FCMs) is an appropriate tool to describe, qualitatively analyze or simulate the behavior of complex systems. FCMs are bipolar fuzzy graphs: their building blocks are the concepts and the arcs. Concepts represent the most important components of the system, the weighted arcs define the strength and direction of cause-effect relationships among them.

FCMs are created by experts in several cases. Despite the best intention the models may contain subjective information even if it was created by multiple experts. An inaccurate model may lead to misleading results, therefore it should be further analyzed before usage. Our method is able to automatically modify the connection weights and to test the effect of these changes. This way the hidden behavior of the model and the most influencing concepts can be mapped. Using the results the experts may modify the original model in order to achieve their goal.

In this paper the internal operation of a department of a bank is modeled by FCM. The authors show how the modification of the connection weights affect the operation of the institute. This way it is easier to understand the working of the bank, and the most threatening dangers of the system getting into an unstable (chaotic or cyclic state) can be identified and timely preparations become possible.
\end{abstract}

Keywords: banking, fuzzy cognitive maps, model uncertainty, multiobjective optimization, Bacterial Evolutionary Algorithm.

\section{$1 \quad$ Introduction}

Fuzzy Cognitive Maps (FCM) are suitable to describe complex systems for decision makers. The models include the most important system components and the direction and strength of relationships among them. There are numerous papers in the literature

adfa, p. 1, 2011.

(C) Springer-Verlag Berlin Heidelberg 2011 
dealing with how to establish models and how to perform simulations with them to support decision making tasks (e.g. [1]). The internal operation of a bank is described and analyzed in this paper with FCM. The behavioral uncertainty and stability of the model were also investigated. The applied method [2] examines the effect of small changes of weight on model behavior. At least two good reasons exists why such an analysis is worth performing.

The original model was provided by experts, and according to our experience the connection matrix provided by humans is sometimes not perfect. It is not surprising that it is sometimes not easy to define the weight of a connection between two components. Even if they do their best, the number of connections is commensurate with the square of the number of components. In our case the investigated system had 13 components, thus the number of connections can theoretically be up to 156 . In general, it is very hard to see the investigated system as a whole with all its details and to choose appropriate weights to represent the real relationships well. If these weights are not properly estimated, the simulation of the system will lead to outcomes that may never occur under real circumstances.

Even if the weights are defined properly the results of this paper may be interesting, because this way a more complete understanding of the model behavior can be obtained. This knowledge may lead to a modified model that eventuates better operation, helps exploring the effects that may jeopardize the operation of the system, etc.

The next section describes briefly the theoretical background of the applied methods, including FCMs in general and the method of uncertainty analysis which is used to find the most interesting, slightly modified model versions. It is followed by the analysis and modeling results of the banking system. Finally, the directions of further improvements and conclusions are summarized.

\section{A short overview of Fuzzy Cognitive Maps}

Axelrod [3] suggested first the use of cognitive maps to support decision making in politics. This idea was later extended to Fuzzy Cognitive Maps (FCMs) by Kosko [4, 5]. FCMs are directed, bipolar fuzzy graphs [6]. The nodes of this structure represent the main components of a system, and are usually called 'concepts'. Their values, which fall into the unit interval $[0,1]$ [7], express the current state of a component (e.g. a partially opened tap) [8]. The arcs among concepts represent the relationships in the system. The weights assigned to the arcs falls in the $[-1,1]$ interval, where the sign of weights define the direction (amplifying, suppressing), and the absolute value of it the strength of the connection.

FCMs are often visualized by a graph or described by the connection matrix which contains the weights of arcs. According to Kosko's original idea, self-loops are not allowed, therefore the main diagonal of the matrix contains only zeros.

The most important capability of FCMs is that simulations can be performed with them in order to predict the future states of the system. If the initial values of concepts are known and also the connection weights are given, the next state of the model can be calculated by Eq. (1). 


$$
A_{i}^{(t+1)}=f\left(\sum_{j=1}^{M} w_{j i} A_{j}^{(t)}+A_{i}^{(t)}\right), i \neq j
$$

In the equation $A_{i}^{(t)}$ represents the value of concept $i$ at time $t$ (also called 'activation' value), $w_{j i}$ is the weight of the directed arc between concepts $j$ and $i, M$ is the number of concepts and $f$ is the threshold function.

We note here that several alternative equations are used besides (1), which alternatives were first proposed in [9]. This version was chosen in this paper because it also uses the current value of the concept when calculating the next value. It means that concepts have a 'memory', and it affects their future states. This behavior is very common in real systems.

The role of the threshold function is to keep the activation values in the allowed range. Several versions of this function are described in the literature [7], but only one of them, the most popular one, namely the sigmoidal function (2) was applied.

$$
f=\frac{1}{1+e^{-\lambda x}}
$$

The function has a $\lambda$ parameter that defines the steepness. The value of $\lambda=5$ is often used in literature, and thus it was chosen by the authors as well. It must be noted however that this parameter value may change the results considerably, and the effect of different values should be further analyzed in the future. A simulation may end up in three different ways [7]:

1. Generally the values of concepts converge to a final, stable value in a dozen discrete time steps. The final vectors of concept values are called the 'fixed point attractors'.

2. Sometimes a series of $n$ state vectors appears repeatedly after a specific time step of the simulation, which is called a 'limit cycle'.

3. The last possible outcome is, when the values of concepts never stabilize, and the model behaves chaotically.

Generally, limit cycles and most of all chaotic behavior should be avoided, because in these cases the future states of the system cannot be predicted. In some specific applications however, e.g. if the goal is predict time series data [10], this behavior can be useful.

\section{Description of the method applied to analyze the uncertainty of connection weights}

The main idea of uncertainty investigation is to modify the connection weights and then to analyze the effect of modifications by simulations. The modifications are directed by the Bacterial Evolutionary Algorithm (BEA) [11-13], in order to find the most 
'interesting' model variants: models with more fixed point attractors and/or chaotic behavior. These outcomes are found here by starting simulations with the same set of 1000 different, randomly generated initial state vectors, the so-called scenarios.

BEA is an evolutionary algorithm which is able to find the quasi-optimum of even a non-continuous, non-linear, multimodal function. It starts with a population of possible solutions and improves these solution candidates (also called 'bacteria') in every consecutive generation. The two main operators, bacterial mutation and gene transfer help to achieve this goal. The first one explores the search space by the random modifications of genetic data, the second one combines the already existing genetic information of the population.

In this specific case, the bacteria of the BEA represent modified connection matrices. In our experiment the population consisted of 50 bacteria, and 5 consecutive generations were created. The weights in an FCM model are represented by real numbers, thus their number is theoretically infinite. Obviously, the number of weights had to be limited to a certain number, in our case $9(-1,-0.75,-0.5, \ldots, 1)$. The investigated model used only five discrete levels according to the linguistic variables chosen by experts. The 9 levels made possible smoother changes in connection weights, and according to our experience, the use of more levels does not provide significant advantages. The concept values in scenarios were also limited to five discrete levels.

In order to limit the computational demand of the algorithm, and because human experts can identify concepts without any connections with high confidence, the elements of the connection matrix containing zeroes were left untouched.

Despite of these restrictions it is easy to see that an exhaustive search would have been impossible in practice: the model under investigation contains 13 concepts, all concepts can have one of the possible 9 levels, thus the number of possible connection matrices can be up to $7.275 \mathrm{e}+148$ (depending on the number of zero weight connections), the number of scenarios with five discrete levels is $1.22 \mathrm{e}+9$. That is why BEA was applied to find the interesting modified models. The $\lambda$ parameter of the threshold function was set to five in all simulations, because it would have further increased the execution time of the program, and simulations themselves can be time consuming tasks. Limit cycles and chaotic behavior cannot be distinguished by the program yet, but the fixed point attractors were recognized automatically.

\section{$4 \quad$ Results}

The model describes the components (concepts) of a bank playing the key roles in this research and their relations including their strength and direction. The concept id's, their corresponding names are collected in Table 1 . The concepts can be categorized into six different groups. Table 2 contains the connection matrix of the model. 
Table 1 Concept IDs, names and categories of the investigated model

\begin{tabular}{ccc} 
Concept ID & Concept name & Category \\
\hline \hline C1 & Clients & \\
C2 & Rules \& regulations & Assets \\
C3 & New IT solutions & \\
\hline C4 & Funding & Money \\
C5 & Cost reduction & Financials \\
\hline C6 & Profit/loss & Human resources \\
C7 & Investments & Staff \\
\hline C8 & New services & Product and Process Development \\
\hline C9 & Quality & \\
C10 & Client development & \\
C12 & Service development & Output measures \\
C13 & Productivity &
\end{tabular}

Table 2 Connection matrix of the FCM model

\begin{tabular}{c|ccccccccccccc} 
& $\mathrm{C} 1$ & $\mathrm{C} 2$ & $\mathrm{C} 3$ & $\mathrm{C} 4$ & $\mathrm{C} 5$ & $\mathrm{C} 6$ & $\mathrm{C} 7$ & $\mathrm{C} 8$ & $\mathrm{C} 9$ & $\mathrm{C} 10$ & $\mathrm{C} 11$ & $\mathrm{C} 12$ & $\mathrm{C} 13$ \\
\hline $\mathrm{C} 1$ & 0 & 0 & 0.5 & 0 & 0 & 0.5 & 1 & 0.5 & 0 & 0.5 & 1 & 0.5 & 0 \\
$\mathrm{C} 2$ & 1 & 0 & 0.5 & 1 & 0 & 0 & 1 & 1 & 0.5 & 0 & 1 & 1 & 0 \\
$\mathrm{C} 3$ & 1 & 0.5 & 0 & 0 & 0 & -1 & 0 & -1 & 1 & 0 & 1 & 1 & 1 \\
$\mathrm{C} 4$ & 0 & 0 & 0 & 0 & 0 & 0 & 0 & 0 & 0 & 0 & 0 & 0 & 0 \\
$\mathrm{C} 5$ & 0 & 0 & 1 & -0.5 & 0 & 0 & 0 & -1 & 0 & 0 & 0 & 1 & 0 \\
$\mathrm{C} 6$ & 0 & 0 & 0 & 0 & -0.5 & 0 & 0 & 0 & 0 & 0 & 0 & 0 & 0 \\
$\mathrm{C} 7$ & 0.5 & 0 & 0.5 & 1 & 0 & 0.5 & 0 & 0 & 0 & -0.5 & 0 & 0 & 0 \\
$\mathrm{C} 8$ & 0 & 0 & 0 & 0 & 0 & -0.5 & 0 & 0 & 0 & 0.5 & 0 & 0 & -0.5 \\
$\mathrm{C} 9$ & 0 & 0 & 0 & 1 & 0 & 0.5 & 0.5 & 0.5 & 0 & -0.5 & 0 & 0.5 & 0 \\
$\mathrm{C} 10$ & 0.5 & 0 & 0 & 0 & 0 & 0 & 0.5 & 0.5 & 0.5 & 0 & 1 & 0 & 0 \\
$\mathrm{C} 11$ & 0 & 0 & 0.5 & 0.5 & 0 & 0 & 0 & 0 & 0.5 & 0.5 & 0 & 0 & 1 \\
$\mathrm{C} 12$ & 0 & 0 & 0.5 & 0.5 & 0 & 0 & 1 & 0 & 0.5 & 0 & 0.5 & 0 & -0.5 \\
$\mathrm{C} 13$ & 0 & 0 & 1 & 0 & 0 & 0.5 & 0 & 0 & 0 & 0 & 1 & 0 & 0
\end{tabular}

First, the original model was investigated by simulations. The sigmoid type threshold function was applied with $\lambda=5$ steepness parameter. Using a thousand element, random-generated set of initial state vectors (scenarios), two possible outcomes were detected by the K-Means clustering method. Both of them were fixed-point attractors (Fps), and most of the concepts had the same final values (1.0), except C6 (Profit/loss) and C8 (Staff). We remark here, that $\mathrm{C} 4$ was an input concept and as such it did not change its value during simulations, but the specific value itself depended on the content of the initial state vector only and was consequently left out from clustering. The final values of concepts are collected in Table 3 . The first FP appeared in $23.1 \%$ of all investigated cases, and the second in the remaining $76.9 \%$. 
Table 3 Fixed-point attractors of the model

\begin{tabular}{cccc} 
Concepts & C1-C3, C5, C7, C9-C13 & C6 & C8 \\
\hline FP\#1 & 1.000 & 0.150 & 0.990 \\
FP\#2 & 1.000 & 0.855 & 0.922
\end{tabular}

Next, the model was further analyzed to reveal the effect of modified connection weights on its behavior. The search directed by BEA found 50 interesting model variants, but considering the size limitations of the paper, only two of them are presented here. The connection matrix of the first variant is shown in Table 4 . The values in parenthesis show the original connection weights to make comparisons easier. This modified model resulted in 12 different fixed-point attractors, but never behaved chaotically or produced limit cycles. The final state vectors are collected in Table 5.

Table 4 Connection matrix of the first model variant

\begin{tabular}{|c|c|c|c|c|c|c|c|c|c|c|c|c|c|}
\hline & $\mathrm{C} 1$ & $\mathrm{C} 2$ & $\mathrm{C} 3$ & $\mathrm{C} 4$ & C5 & C6 & C7 & C8 & C9 & $\mathrm{C} 10$ & $\mathrm{C} 11$ & $\mathrm{C} 12$ & $\mathrm{C} 13$ \\
\hline $\mathrm{C} 1$ & 0 & 0 & $\begin{array}{l}-0.75 \\
(0.5)\end{array}$ & 0 & 0 & $1(0.5)$ & $-1(1)$ & $\begin{array}{l}-0.25 \\
(0.5)\end{array}$ & 0 & $-0.5(0.5)$ & $0.5(1)$ & $\begin{array}{l}0.75 \\
(0.5)\end{array}$ & 0 \\
\hline $\mathrm{C} 2$ & 1 & 0 & $\begin{array}{l}0.75 \\
(0.5)\end{array}$ & $-0.5(1)$ & 0 & 0 & $0.5(1)$ & $-0.25(1)$ & $0(0.5)$ & 0 & $0.25(1)$ & 1 & 0 \\
\hline $\mathrm{C} 3$ & $0(1)$ & $\begin{array}{l}0.75 \\
(0.5)\end{array}$ & 0 & 0 & 0 & $\begin{array}{c}-0.25 \\
(-1)\end{array}$ & 0 & -1 & $\begin{array}{c}-0.75 \\
(1)\end{array}$ & 0 & $0.75(1)$ & $\begin{array}{c}-0.75 \\
(1)\end{array}$ & 1 \\
\hline $\mathrm{C} 4$ & 0 & 0 & 0 & 0 & 0 & 0 & 0 & 0 & 0 & 0 & 0 & 0 & 0 \\
\hline $\mathrm{C} 5$ & 0 & 0 & $-0.5(1)$ & $0(-0.5)$ & 0 & 0 & 0 & $1(-1)$ & 0 & 0 & 0 & 1 & 0 \\
\hline C6 & 0 & 0 & 0 & 0 & $\begin{array}{l}0.75 \\
(-.5)\end{array}$ & 0 & 0 & 0 & 0 & 0 & 0 & 0 & 0 \\
\hline C7 & $1(0.5)$ & 0 & $1(0.5)$ & $-0.25(1)$ & 0 & $-1(0.5)$ & 0 & 0 & 0 & $\begin{array}{c}-0.75(- \\
0.5)\end{array}$ & 0 & 0 & 0 \\
\hline $\mathrm{C} 8$ & 0 & 0 & 0 & 0 & 0 & $-1(-0.5)$ & 0 & 0 & 0 & $\begin{array}{l}-0.25 \\
(0.5)\end{array}$ & 0 & 0 & -0.5 \\
\hline C9 & 0 & 0 & 0 & 1 & 0 & $\begin{array}{l}-0.25 \\
(0.5)\end{array}$ & $1(0.5)$ & $\begin{array}{l}0.75 \\
(0.5)\end{array}$ & 0 & $\begin{array}{c}0.75 \\
(-0.5)\end{array}$ & 0 & $\begin{array}{l}-0.5 \\
(0.5)\end{array}$ & 0 \\
\hline $\mathrm{C} 10$ & $\begin{array}{l}-0.25 \\
(0.5)\end{array}$ & 0 & 0 & 0 & 0 & 0 & $\begin{array}{c}-1 \\
(0.5)\end{array}$ & $\begin{array}{l}-0.25 \\
(0.5)\end{array}$ & $-1(0.5)$ & 0 & $\begin{array}{c}-0.75 \\
(1)\end{array}$ & 0 & 0 \\
\hline C11 & 0 & 0 & $0(0.5)$ & $\begin{array}{c}-0.75 \\
(0.5)\end{array}$ & 0 & 0 & 0 & 0 & $1(0.5)$ & $-1(0.5)$ & 0 & 0 & $\begin{array}{l}-1 \\
(1)\end{array}$ \\
\hline C12 & 0 & 0 & $\begin{array}{c}-0.75 \\
(0.5)\end{array}$ & 0.5 & 0 & 0 & $\begin{array}{l}-0.5 \\
(1)\end{array}$ & 0 & $\begin{array}{l}0.25 \\
(0.5)\end{array}$ & 0 & $\begin{array}{l}0.25 \\
(0.5)\end{array}$ & 0 & $\begin{array}{l}0.75 \\
(-.5)\end{array}$ \\
\hline $\mathrm{C} 13$ & 0 & 0 & 1 & 0 & 0 & $\begin{array}{c}-0.75 \\
(0.5)\end{array}$ & 0 & 0 & 0 & 0 & $-0.5(1)$ & 0 & 0 \\
\hline
\end{tabular}

Table 5 Fixed-point attractors of the first model variant

\begin{tabular}{|c|c|c|c|c|c|c|c|c|c|c|c|c|}
\hline FP ID & $\mathrm{C} 1$ & $\mathrm{C} 2$ & $\mathrm{C} 3$ & C5 & C6 & C7 & C8 & C9 & $\mathrm{C} 10$ & $\mathrm{C} 11$ & $\mathrm{C} 12$ & $\mathrm{C} 13$ \\
\hline FP\#1 & 0.826 & 1.000 & 1.000 & 1.000 & 0.026 & 1.000 & 0.112 & 1.000 & 0.000 & 0.982 & 0.995 & 0.999 \\
\hline FP\#2 & 0.037 & 1.000 & 0.997 & 1.000 & 0.026 & 1.000 & 0.787 & 1.000 & 0.000 & 0.960 & 0.996 & 0.999 \\
\hline FP\#3 & 0.108 & 1.000 & 1.000 & 1.000 & 0.026 & 1.000 & 0.112 & 1.000 & 0.000 & 0.943 & 0.997 & 0.999 \\
\hline FP\#4 & 0.006 & 1.000 & 0.848 & 1.000 & 0.026 & 1.000 & 0.785 & 1.000 & 0.000 & 0.053 & 0.998 & 1.000 \\
\hline FP\#5 & 0.008 & 1.000 & 0.997 & 1.000 & 0.026 & 1.000 & 0.112 & 1.000 & 0.000 & 0.046 & 0.998 & 1.000 \\
\hline FP\#6 & 0.994 & 1.000 & 0.015 & 1.000 & 0.026 & 1.000 & 0.989 & 1.000 & 0.000 & 0.999 & 0.998 & 0.138 \\
\hline FP\#7 & 0.188 & 1.000 & 0.109 & 1.000 & 0.026 & 0.994 & 0.796 & 1.000 & 0.000 & 0.036 & 1.000 & 0.995 \\
\hline FP\#8 & 0.993 & 1.000 & 0.046 & 1.000 & 0.026 & 1.000 & 0.981 & 1.000 & 0.000 & 0.998 & 0.999 & 0.338 \\
\hline FP\#9 & 0.026 & 1.000 & 0.488 & 1.000 & 0.026 & 0.998 & 0.788 & 1.000 & 0.000 & 0.065 & 1.000 & 0.999 \\
\hline FP\#10 & 0.621 & 1.000 & 1.000 & 1.000 & 0.026 & 1.000 & 0.112 & 1.000 & 0.000 & 0.965 & 0.997 & 0.999 \\
\hline FP\#11 & 0.392 & 1.000 & 0.098 & 1.000 & 0.026 & 0.998 & 0.799 & 1.000 & 0.000 & 0.027 & 1.000 & 0.995 \\
\hline FP\#12 & 0.870 & 1.000 & 0.120 & 1.000 & 0.026 & 1.000 & 0.795 & 1.000 & 0.000 & 0.047 & 1.000 & 0.995 \\
\hline
\end{tabular}

Some interesting phenomena can be observed in Table 5. The value of C8 was very high in the original model $(\approx 0.9)$, but it can be close to zero in the modified model. The values of $\mathrm{C} 3, \mathrm{C} 11$ and $\mathrm{C} 13$ were one, but in the modified model various values can be observed. The FP values of C2, C5, C7, C9 and C12 were 1 in the original model, it 
practically did not changed despite the modifications. C6 had two different values in the original model, but only a single one after the modifications. $\mathrm{C} 10$ changed its value from 1 to 0 .

The second selected model variant example behaved in a different way: it had only 9 FPs, but 882 simulations out of 1000 did not result in stable state (chaotic behavior or limit cycles).

Table 6 Connection matrix of the second model variant

\begin{tabular}{|c|c|c|c|c|c|c|c|c|c|c|c|c|c|}
\hline & $\mathrm{C} 1$ & $\mathrm{C} 2$ & C3 & $\mathrm{C} 4$ & C5 & C6 & C7 & $\mathrm{C} 8$ & C9 & $\mathrm{C} 10$ & C11 & $\mathrm{C} 12$ & $\mathrm{C} 13$ \\
\hline $\mathrm{C} 1$ & 0 & 0 & $\begin{array}{l}0.75 \\
(0.5)\end{array}$ & 0 & 0 & $\begin{array}{l}-0.75 \\
(0.5)\end{array}$ & $-0.25(1)$ & $\begin{array}{l}0.25 \\
(0.5)\end{array}$ & 0 & $-1(0.5)$ & $0.25(1)$ & $1(0.5)$ & 0 \\
\hline $\mathrm{C} 2$ & $-1(1)$ & 0 & $\begin{array}{l}-0.75 \\
(0.5)\end{array}$ & $-1(1)$ & 0 & 0 & $0.25(1)$ & $-1(1)$ & $\begin{array}{l}0.75 \\
(0.5)\end{array}$ & 0 & $0.25(1)$ & $-1(1)$ & 0 \\
\hline $\mathrm{C} 3$ & $-1(1)$ & 0.5 & 0 & 0 & 0 & $\begin{array}{c}-0.25 \\
(-1)\end{array}$ & 0 & -1 & $-0.5(1)$ & 0 & $-0.75(1)$ & $-1(1)$ & $\begin{array}{l}0.5 \\
(1)\end{array}$ \\
\hline $\mathrm{C} 4$ & 0 & 0 & 0 & 0 & 0 & 0 & 0 & 0 & 0 & 0 & 0 & 0 & 0 \\
\hline $\mathrm{C} 5$ & 0 & 0 & $-0.25(1)$ & $\begin{array}{c}0.5 \\
(-0.5)\end{array}$ & 0 & 0 & 0 & $\begin{array}{c}-0.75 \\
(-1)\end{array}$ & 0 & 0 & 0 & $-0.5(1)$ & 0 \\
\hline $\mathrm{C} 6$ & 0 & 0 & 0 & 0 & $\begin{array}{l}0.75 \\
(-.5)\end{array}$ & 0 & 0 & 0 & 0 & 0 & 0 & 0 & 0 \\
\hline $\mathrm{C} 7$ & $\begin{array}{l}-0.25 \\
(0.5)\end{array}$ & 0 & $-0.5(0.5)$ & $0.75(1)$ & 0 & 0.5 & 0 & 0 & 0 & $-1(-0.5)$ & 0 & 0 & 0 \\
\hline $\mathrm{C} 8$ & 0 & 0 & 0 & 0 & 0 & $\begin{array}{c}0.75 \\
(-0.5)\end{array}$ & 0 & 0 & 0 & $\begin{array}{l}-0.25 \\
(0.5)\end{array}$ & 0 & 0 & $\begin{array}{c}-1 \\
(-0.5)\end{array}$ \\
\hline $\mathrm{C} 9$ & 0 & 0 & 0 & $-0.75(1)$ & 0 & $-0.5(0.5)$ & $\begin{array}{l}0.25 \\
(0.5)\end{array}$ & $0(0.5)$ & 0 & $0(-0.5)$ & 0 & $\begin{array}{c}-0.5 \\
(0.5)\end{array}$ & 0 \\
\hline $\mathrm{C} 10$ & 0.5 & 0 & 0 & 0 & 0 & 0 & $1(0.5)$ & $\begin{array}{l}0.75 \\
(0.5)\end{array}$ & 0.5 & 0 & $-0.25(1)$ & 0 & 0 \\
\hline C11 & 0 & 0 & $\begin{array}{l}0.25 \\
(0.5)\end{array}$ & $\begin{array}{l}-0.25 \\
(0.5)\end{array}$ & 0 & 0 & 0 & 0 & $1(0.5)$ & $\begin{array}{c}-0.25 \\
(0.5)\end{array}$ & 0 & 0 & $0(1)$ \\
\hline $\mathrm{C} 12$ & 0 & 0 & $1(0.5)$ & $\begin{array}{l}-0.75 \\
(0.5)\end{array}$ & 0 & 0 & $0.5(1)$ & 0 & $0(0.5)$ & 0 & $\begin{array}{l}-0.75 \\
(0.5)\end{array}$ & 0 & $\begin{array}{c}0 \\
(-0.5)\end{array}$ \\
\hline $\mathrm{C} 13$ & 0 & 0 & $0.5(1)$ & 0 & 0 & $\begin{array}{l}0.75 \\
(0.5)\end{array}$ & 0 & 0 & 0 & 0 & $0.75(1)$ & 0 & 0 \\
\hline
\end{tabular}

Table 7 Fixed-point attractors of the second model variant

\begin{tabular}{ccccccccccccc} 
FP ID & $\mathrm{C} 1$ & $\mathrm{C} 2$ & $\mathrm{C} 3$ & $\mathrm{C} 5$ & $\mathrm{C} 6$ & $\mathrm{C} 7$ & $\mathrm{C} 8$ & $\mathrm{C} 9$ & $\mathrm{C} 10$ & $\mathrm{C} 11$ & $\mathrm{C} 12$ & $\mathrm{C} 13$ \\
\hline FP\#1 & 0.053 & 0.000 & 0.000 & 0.010 & 0.993 & 0.957 & 0.846 & 0.012 & 1.000 & 0.964 & 0.883 & 1.000 \\
FP\#2 & 0.001 & 0.020 & 0.001 & 0.201 & 0.985 & 0.979 & 0.834 & 0.065 & 1.000 & 0.968 & 0.103 & 1.000 \\
FP\#3 & 0.970 & 0.000 & 0.000 & 0.994 & 0.027 & 0.883 & 0.002 & 0.007 & 1.000 & 0.158 & 0.923 & 0.997 \\
FP\#4 & 0.002 & 0.280 & 0.001 & 0.046 & 0.992 & 0.137 & 0.844 & 0.182 & 1.000 & 0.990 & 0.041 & 1.000 \\
FP\#5 & 0.002 & 0.887 & 0.006 & 0.045 & 0.992 & 0.134 & 0.844 & 0.180 & 1.000 & 0.990 & 0.041 & 1.000 \\
FP\#6 & 0.002 & 0.995 & 0.001 & 0.046 & 0.992 & 0.137 & 0.844 & 0.880 & 1.000 & 1.000 & 0.039 & 1.000 \\
FP\#7 & 0.013 & 0.001 & 0.000 & 0.024 & 0.992 & 0.979 & 0.845 & 0.013 & 1.000 & 0.957 & 0.656 & 1.000 \\
FP\#8 & 0.033 & 0.044 & 0.000 & 0.073 & 0.991 & 0.829 & 0.135 & 0.023 & 1.000 & 0.977 & 0.961 & 1.000 \\
FP\#9 & 0.020 & 0.000 & 0.000 & 0.061 & 0.991 & 0.998 & 0.843 & 0.001 & 1.000 & 0.146 & 0.950 & 1.000
\end{tabular}

The FP values of $\mathrm{C} 1, \mathrm{C} 2, \mathrm{C} 5, \mathrm{C} 7, \mathrm{C} 9, \mathrm{C} 11$ and $\mathrm{C} 12$ were exclusively 1 , but in the modified model their values could be significantly different. The value of $\mathrm{C} 3$ was always 1 in the original model, and it practically did not change after the model modifi- 
cations. C6 had two different values (a low and a high one) in case of both model versions, but these pairs of values are not the same. C8 had two high FP values in the original model, but hold two smaller values in the modified model. The FP values of C10 and C13 are still 1.

\section{Conclusions and future research}

The applied method generated small modifications on FCM models that led to very different model behaviors. It proved to be very useful to find relationships that are sensitive to changes and may cause unexpected simulation results. These connection weights need further investigations by experts of the specific field.

The method should be further improved, however. The extent of weight modifications should be limited to a certain degree, depending on the application area. The effect of modified lambda value should be also analyze, because it may also heavily affect the simulation results. The differentiation of chaotic cases and limit cycles would be also important, and the improvement of some implementation details should be improved.

Acknowledgement. This research was supported by the National Research, Development and Innovation Office (NKFIH) K108405 and by the EFOP-3.6.2-16-2017-00015 "HU-MATHS-IN; Intensification of the activity of the Hungarian Industrial Innovation Service Network" grant.

Supported BY the ÚNKP-17-4 New National Excellence Program of the Ministry of Human Capacities.

\section{References}

1. Papageorgiou, E. I. (Ed.). (2013). Fuzzy Cognitive Maps for Applied Sciences and Engineering: From Fundamentals to Extensions and Learning Algorithms (Vol. 54). Springer Science \& Business Media.

2. Miklós F. Hatwágner, M. F., Kóczy, L. T. (2016). Uncertainty Tolerance and Behavioral Stability Analysis of Fixed Structure Fuzzy Cognitive Maps. Proceedings of $8^{\text {th }}$ European Symposium on Computational Intelligence and Mathematics (ESCIM 2016), Sofia, Bulgaria (pp. 15-23).

3. Axelrod, R. (Ed.). (1976). Structure of decision: The cognitive maps of political elites. Princeton university press.

4. Kosko, B. (1986). Fuzzy cognitive maps. International Journal of man-machine studies, 24(1), 65-75.

5. Kosko, B. (1988). Hidden patterns in combined and adaptive knowledge networks. International Journal of Approximate Reasoning, 2(4), 377-393.

6. Zhang, W. R. (1998, May). (Yin)(Yang) bipolar fuzzy sets. In Fuzzy Systems Proceedings, 1998. IEEE World Congress on Computational Intelligence. The 1998 IEEE International Conference on (Vol. 1, pp. 835-840). IEEE.

7. Tsadiras, A. K., (2007). Inference using Binary, Trivalent and Sigmoid Fuzzy Cognitive Maps, Proceedings of the 10th International Conference on Engineering Applications of Neural Networks (EANN 2007) (vol. 284, pp. 327-334) 
8. Parsopoulos, K. E., Papageorgiou, E. I., Groumpos, P. P., \& Vrahatis, M. N. (2003, December). A first study of fuzzy cognitive maps learning using particle swarm optimization. In Evolutionary Computation, 2003. CEC'03. The 2003 Congress on (Vol. 2, pp. 1440-1447). IEEE.

9. Stylios, C. D., \& Groumpos, P. P. (1999, June). Mathematical formulation of fuzzy cognitive maps. In Proceedings of the 7th Mediterranean Conference on Control and Automation (pp. 2251-2261).

10. Lu, W., Pedrycz, W., Liu, X., Yang, J., \& Li, P. (2014). The modeling of time series based on fuzzy information granules. Expert Systems with Applications, 41(8), 3799-3808.

11. Nawa, N. E., \& Furuhashi, T. (1998, April). A study on the effect of transfer of genes for the bacterial evolutionary algorithm. In Knowledge-Based Intelligent Electronic Systems, 1998. Proceedings KES'98. 1998 Second International Conference on (Vol. 3, pp. 585-590). IEEE.

12. Nawa, N. E., \& Furuhashi, T. (1999). Fuzzy system parameters discovery by bacterial evolutionary algorithm. Fuzzy Systems, IEEE Transactions on, 7(5), 608-616.

13. Nawa, N. E., Hashiyama, T., Furuhashi, T., \& Uchikawa, Y. (1997, April). A study on fuzzy rules discovery using pseudo-bacterial genetic algorithm with adaptive operator. In Evolutionary Computation, 1997. IEEE International Conference on (pp. 589-593). IEEE. 